\title{
LA MIGRACIÓN: \\ ESTUDIO SOBRE LAS REMESAS \\ DE DIVISAS QUE INGRESAN EN EL \\ ECUADOR
}

\section{Dra. Ana Luz Borrero Vega}

Catedrática de la Universidad de Cuenca, Directora Académica de la Maestría en Población y Desarrollo Local Sustentable y Directora de la Escuela de Filosofía y Ciencias Sociales de la Universidad de Cuenca.

\section{INTRODUCCIÓN}

$\mathrm{L}$

a última década en el Ecuador puede ser calificada como la década de la emigración, este fenómeno involucra cada vez a un mayor número de familias e individuos. La emigración y el abandono voluntario del país, del terruño y de la "patria", se convierte en el principal sueño y utopía de miles de ecuatorianos, quiénes buscan en Estados Unidos y últimamente en España la tierra de la promisión. El "sueño americano" que cada vez se hace más inalcanzable por las trabas y dificultades, la gente común, la gente del pueblo, el trabajador migratorio ha pensado en cambiar de destino, ahora busca su futuro en Europa, donde España e Italia, y en menor medida otros países, particularmente Inglaterra, es una de las metas de esta diáspora de ecuatorianos.

Según datos de la Dirección Nacional de Migración del Ecuador durante los tres últimos años salieron del país un 1'220 362 ecuatorianos y los países a donde se dirigieron fueron a Estados Unidos, España, Italia, Alemania e Inglaterra, de estos han regresado a Ecuador 917826 de forma voluntaria, esto quiere decir que unos 302000 ecuatorianos se han quedado fuera del país en estos últimos años, de estos 3427 han sido repatriados por no tener documentos reglamentarios, unos pocos miles han regresado procedentes de España para regularizar su situación y volver a ese país con un contrato de trabajo y residencia. Estos números son de aquellos que salieron por vías legales, el total de personas que salieron irregularmente es indudablemente mayor y no es posible establecer o determinar su número exacto. El volu- 
men total de emigrantes, el porcentaje que representa en la población de las provincias y ciudades del Austro, en especial en Cuenca, no lo podemos conocer hasta que haya un dato certero proveniente del censo nacional que se realizó en noviembre de 2001. Esto ha llevado a que se exageren cifras del número de migrantes y del número de familias involucradas, en todo caso, una estimación podría señalar de una cifra que vaya del 10 al $20 \%$ de la población de cada cantón y parroquia del Azuay y Cañar (según la Asociación de Defensa del Emigrante del Azuay, solo el año pasado salieron de Cuenca y el Azuay un total de 32256 personas).

\section{Causas de la migración}

Entre las causas más sobresalientes de la emigración están sin duda la crisis económica, el deterioro de las condiciones de vida, las altas tasas de inflación, la dolarización, la situación de incertidumbre e inseguridad política y una creciente pobreza, disminución de empleo y pérdida de capacidad adquisitiva e ingresos. También a estas causas hay que añadir aspectos culturales y sociales, de una sociedad que mira con buenos ojos a quién se arriesga a migrar y luego obtiene éxito económico, consigue mejorar su estatus y demuestra que es capaz de triunfar.

Este proceso migratorio ecuatoriano que involucra a todo el país, pero que tiene como epicentro la región centro-sur andina del Ecuador (particularmente las provincias del Azuay y del Cañar), es parte de un fenómeno latinoamericano que se inicia desde los años setenta y que se agudiza con las últimas crisis. La mayoría de esta emigración es ilegal con todos los riesgos que esto conlleva. Es una migración laboral o de trabajo que crea problemas tanto en los lugares de origen como en los lugares de destino.

\section{Origen de los ecuatorianos migrantes}

Los ecuatorianos residentes en Europa, particularmente en España, provienen de todo el país, pero hay que resaltar entre otros a lojanos, manabitas, azuayos, cañarenses y orenses. Algunos de los migrantes son quiteños y guayaquileños, pero la mayoría tiene su origen en medianas localidades de las provincias antes citadas. 
En Europa los trabajadores migrantes ecuatorianos se dedican a labores domésticas, prestación de servicios y trabajos agrícolas. Por ejemplo, de la última oleada de ecuatorianos migrantes, su trabajo está en el agro, ya sea en cosecha de melones, la siembra y cosecha de brócoli, trabajos temporales, servicio doméstico, cuidado de ancianos y niños, son las principales opciones de los ecuatorianos migrantes. No hay que descartar por supuesto que ciertos profesionales y con alto nivel de capacitación se integran rápidamente a la sociedad española y en menor medida a otras sociedades europeas, tal es el caso de médicos, ingenieros de sistemas y otros. Pero, no son la mayoría, el resto va a trabajar en el sector agropecuario, en la construcción como mano de obra no calificada, en hostelería, comercio al por menor y otras actividades.

\section{Las remesas de migrantes}

Lo positivo de esta migración es indudablemente económico, las remesas de ecuatorianos migrantes para el año 2000 según datos del Banco Central del Ecuador (enero del 2001) fueron de 1,205 millones de dólares, de los cuáles 551 millones llegan a la provincia del Azuay el $45 \%$ del total (ver cuadro N.1).

Nadie duda en el Ecuador que el sustento de la migración procede de las remesas. El ingreso de divisas por este concepto es superior a varios rubros de exportación, solamente lo supera el petróleo.

Se prevee que para el 2001 llegarán al Ecuador por esta razón un total de 1,330 millones de dólares, que se convierten en el segundo rubro después de las exportaciones de petróleo, superando todos los otros ingresos que tiene el Ecuador por exportaciones.

Después del Azuay la segunda provincia que aporta con mayor número de remesas es Manabí, una de las provincias costeñas con alta emigración.

Según provincias el reparto de las remesas es el que sigue: Azuay como se dijo con más del 45\%, Manabí con 5,40\%, Loja con el $4,40 \%$, Cañar con el $3,70 \%$ y el resto del país con el $40,9 \%$. 


\section{Cuadro № 1}

Cifras de las remesas en dólares al Ecuador (en millones)

\begin{tabular}{|c|c|c|c|c|c|c|}
\hline Año & Azuay & Cañar & Loja & Manabí & Resto del país & Total \\
\hline 1995 & 174 & 15 & 17 & 21 & 154 & 382 \\
\hline 1996 & 228 & 19 & 22 & 28 & 208 & 505 \\
\hline 1997 & 294 & 22 & 27 & 34 & 266 & 644 \\
\hline 1998 & 362 & 29 & 36 & 43 & 325 & 794 \\
\hline 1999 & 495 & 40 & 47 & 58 & 444 & 1084 \\
\hline 2000 & 551 & 45 & 52 & 64 & 493 & 1205 \\
\hline total & I2104 & 170 & 201 & 248 & 1890 & 4614 \\
\hline
\end{tabular}

Fuente: Banco Central del Ecuador. Diario El Mercurio, 27 de Diciembre, 2000.

El dinero enviado por los residentes o emigrantes hacia el Ecuador es sin duda un flujo de divisas importante, que ingresa sin una contrapartida, la fuente son las remesas de los trabajadores migrantes. El Banco Central para contabilizar estos ingresos la denomina transferencias corrientes, los datos son estimaciones, ya que la información para la cuantificación es muy compleja y difícil. Las remesas llegan a través de distintas formas, una de las conocidas es la de las empresas de transferencia de dinero, por ejemplo Delgado Travel, Western Union, Money Gram, etc. Según declaraciones de estas compañías hechas a la Revista Gestión en marzo de 2001, por ejemplo para Money Gram Estados Unidos es el principal país de origen de las transferencias, con el 40 ó 50\% de la participación, seguido de España con el segundo lugar y un 25 ó $30 \%$ de las preferencias de migrantes, en tercer lugar están países europeos como Italia, Bélgica, Inglaterra. El volumen de las remesas tiene un promedio de 400 ó 450 dólares por vez, las transferencias desde Europa van de 600 a 700 dólares promedio.

A pesar de que existe un enorme crecimiento del envío de remesas en los últimos años, el Estado no ha regularizado la presencia de ciertas compañías que se hacen cargo del traslado o 
transferencia de estos recursos. No están bajo la supervisión por ejemplo de la Superintendencia de Bancos, quedan fuera de la ingerencia del Banco Central, no es fácil obtener información veraz.

Si comparamos los rubros de las remesas con otros ingresos del país, podemos señalar lo siguiente: el primer producto de exportación y fuente de divisas es el petróleo y los derivados, con el $34 \%$ del total, luego están las remesas con el $15,1 \%$ y en tercer lugar el banano con $12,3 \%$, el turismo con $5,6 \%$ y después el camarón con el $4 \%$, los restantes ingresos están muy por debajo.

Con lo que se puede decir que el principal producto de "exportación" después del petróleo es la mano de obra o trabajadores ecuatorianos.

\section{El uso de las remesas}

A más del uso de remesas para satisfacer necesidades básicas de las familias involucradas, estas remesas indudablemente se utilizan en sectores como el de los bienes raíces, financieras y bienes muebles de línea blanca y café. El comercio, de manera particular almacenes, supermercado y otros sectores de servicios, como el educativo, el de salud, hotelería y restaurantes se han beneficiado con esos ingresos y es indudable el crecimiento de los correos particulares que traen y llevan remesas de familiares de migrantes; de hecho, hasta antes de la dolarización, un negocio lucrativo fueron las cambiarias y agencias bancarias en los lugares más recónditos de la provincia y la región. Según autoridades de la Cámara de Comercio, en Cuenca, la migración causa pérdida de trabajadores por un lado y un incremento del consumo de bienes de lujo, pero las inversiones de los migrantes no son en el sector productivo, por tanto no crea empleos ni riqueza futura. La economía local, especialmente la de los lugares de origen de la migración, tal es el caso de Cuenca, pueden ver un crecimiento en el consumo y una reactivación económica local, en particular lo que hace referencia a la construcción y el comercio, pero es más difícil notar aspectos positivos en otros sectores de la economía.

La familia suele encargarse de la construcción de la casa o la compra de terrenos, de bienes y otros enseres. Los parientes 
que se quedan tienen a su cargo cuidar de los bienes que han adquirido los emigrantes.

\section{Efectos de la migración}

Los impactos de la migración de ecuatorianos al extranjero, son indudablemente muy variados, hay algunos que afectan a la población directamente, los impactos demográficos, que entre otros es la disminución sustancial de los lugares de origen de la migración, cambios en la estructura de la población en lo que respecta a sexo y edad, con la consecuente feminización de las poblaciones o desigualdad en la distribución por edad, con una mayoría de niños y ancianos, ya que los jóvenes adultos, en edad de trabajar, han migrado. Existen por supuesto consecuencias de carácter demográfico ya que hay un descenso de la fecundidad marital, cambios en el perfil epidemiológico de la población, donde hay que incluir el VIHISIDA, que afecta a ciertos migrantes de retorno. Otro aspecto, que no puede ser considerado positivo, es el del impacto psicológico y afectivo, ya que los que se han quedado sienten desesperanza, depresión, síndrome de ausencia, entre otros.

Los sueños de un futuro mejor se ven recompensados en mejores ingresos, en la compra de tierras agrícolas, en una casa de 3 pisos, en un vehículo último modelo a la puerta, en el mejor colegio para los hijos, en la ropa de marca y de moda, pero a su vez la cara negativa es la desintegración y desestructuración de la familia, nuevos estilos de vida que rompen con la cultura tradicional, cambios en los valores culturales, desadaptación, pérdida de identidad, erosión de la organización comunitaria en el campo y en comunidades rurales y redefinición de roles en el hogar; existe, en los últimos años, un aumento de la delincuencia juvenil, bajo rendimiento y deserción escolar, abandono de esposas y padres ancianos, y una cada vez creciente migración femenina. De entre estas últimas consecuencias podemos rescatar algunos elementos positivos, por ejemplo la sobreestimación de las mujeres y el nuevo papel para ellas en las decisiones familiares y comunitarias.

\section{Consecuencias en la cultura y en el territorio}

La migración deja sus huellas tanto en los territorios como en la cultura: en lo territorial hay un crecimiento desmedido de las 
zonas urbanas con una presión hacia los centros poblados o parroquias rurales suburbanas en el caso de Cuenca y también Azogues, ciertas parroquias rurales han crecido desmesuradamente, sin orden ni planificación, como el caso de Ricaurte, San Joaquín y Déleg. Las dificultades de crear una red de servicios básicos en zonas de rápida expansión es una de las pautas de este desmesurado crecimiento, el sueño del migrante exitoso es la de construir una casa que muestre su poderío, de tres pisos o más, juego de techos, ventanas y garajes, aun en los lugares más apartados, incluso cerca del páramo o en zonas totalmente marginales, se ha llegado en ciertos casos a crear conflictos con áreas de protección y desmedida tala de vegetación nativa, bosques primarios y expansión de la frontera agrícola.

La importación de estilos arquitectónicos de la gran ciudad, el exceso y abuso del hormigón y del bloque hacen que las zonas de alta emigración pierdan su identidad patrimonial y armonía arquitectónica frente a verdaderos "monstruos de cemento" a veces en la mitad de un pequeño villorrio que mantenía una graciosa armonía con el paisaje y entorno; ante la fiebre de la construcción de los "residentes", estos recintos, poblados, parroquias o cantones, pierden su potencial cultural y su futuro como lugares de turismo rural y parte del turismo nacional o internacional. La fisonomía de los poblados no es la única que cambia, también lo hacen las funciones de los pueblos, existe abandono de las labores agrícolas y la preferencia por actividades comerciales y secundarias, que hace que el paisaje del pueblo y de la periferia cambien radicalmente.

Este cambio de fisonomía con viviendas urbanas en áreas rurales, la mayoría lugares desocupados porque sus miembros moran en el extranjero, dan lugar a una alta demanda de bienes inmuebles, de terrenos, propiedades, fincas, haciendas, etc., la alta demanda ha llegado a impactar negativamente en los precios de los bienes raíces. La tierra urbana y rural llegan a ser una de las más caras del país. El suelo urbano y el rural de Cuenca y su región están sobredimensionados en su precio, existen precios irrealmente inflados por la demanda de los migrantes, familiares o "residentes". Los migrantes desean volver a sus terruños y lugares de origen, sueñan con construir una casa o comprar tierras agrícolas donde nacieron, pagan el precio que les piden, aun que el mis- 
mo sea demasiado alto. Ningún no migrante puede competir con esos precios, la población que no ha migrado no tiene la afluencia y facilidad de dólares para acceder en igualdad de condiciones a un terreno urbano o rural. Zonas rurales alejadas llegan a valorarse sobre los 40,000 dólares la hectárea por ejemplo zona ganadera de Pacay-San Fernando, Azuay, zonas suburbanas marginales llegan a valorarse 500,000 dólares la hectárea (zona de la periferia de Cuenca hacia Barabón) y lo peor está ya en los centros urbanos. La diferencia entre las familias de migrantes y no migrantes y su posibilidad de construir una vivienda o adquirir una tierra productiva es abismal.

Otro problema de la emigración es el de los costos de la construcción, la mano de obra especializada o no de la construcción en Cuenca y su región es la más cara del país, la hora promedio del asalariado urbano en el país es de 0.76 dólares, cuando el "maestro albañil" en Cuenca y zonas próximas cobra 4 dólares la hora. No solo la mano de obra es más cara, también los materiales de construcción, tal es el caso del costo del metro cúbico de arena, según los arquitectos constructores, para mayo de 2001, el precio asciende a 20 dólares, cuando por la misma cantidad se paga en Guayaquil y Quito, ciudades más grandes y con más demanda, solamente 8 dólares por metro cúbico.

Para los cultivos hortícolas de San Joaquín, trabajos de la construcción y otras actividades productivas, se tiene que buscar mano de obra de las provincias aledañas o de la Costa o la Sierra Norte. Campesinos del Cañar, de Chimborazo o de Loja (zona de Saraguro), realizan ahora el trabajo agrícola o de la construcción en Cuenca. Los industriales y representantes de otros sectores productivos han mostrado constantemente que en los últimos años hay escasez de mano de obra en Cuenca, como ejemplo está el caso de la hotelería y hostelería, uno de los problemas más serios es el de conseguir empleados para estas actividades, la mayoría ha migrado para Estados Unidos y España, las personas con capacitación y experiencia han dejado sus empleos. La emigración de personas en edad de trabajar, hace que si bien en el país hay un desempleo abierto alto, para el año 2000, según INEC, Cuenca tiene la tasa de desempleo más bajo del país con un 7,1 , frente a la tasa nacional que supera el $12 \%$. 
Otro efecto de la emigración es que una alta demanda de productos y la especulación lleva a que exista en Cuenca y la región una constante alza de precios de productos varios, alimentos, vestido y habitación son según los informes últimos de INEC, de entre los más caros del país, con la tasa de inflación más alta (15\% marzo del 2001), esto afecta negativamente a quiénes no migramos y tenemos un salario local, es decir a la mayoría de la población. Afecta enormemente a los ancianos y jubilados, a las mujeres jefes de hogar y a los niños de la región, muchos de ellos "huérfanos de la migración". La inflación de los precios de los bienes de subsistencia a pesar de la dolarización es un problema de difícil solución y no hay conducción política-económica que se empeñe en superar este problema. Entre los costos que se han inflado naturalmente están los de educación y otros servicios.

Finalmente, el efecto de los impactos en la cultura e identidad cultural están patentes en los cambios tangibles como la arquitectura, moda y uso del suelo, pero hay elementos más sutiles de la cultura intangible que tienen que estudiarse con mayor detenimiento. Lo negativo tal vez es más impactante que lo positivo, por lo pronto, esbozando lo positivo podríamos señalar que los migrantes han incentivado a través del priostazgo las fiestas tradicionales religiosas, pero al mismo tiempo, música "heavy metal" sustituye a la chirimía y al acordeón, los jóvenes son los que más han abandonado prácticas culturales locales y nativas. 